\title{
Standard operating procedure (SOP) for disk diffusion-based quorum sensing inhibition assays
}

\author{
MÁRIÓ GAJDÁCS ${ }^{1,2^{*}}$, GABRIELLA SPENGLER ${ }^{1}$ \\ ${ }^{1}$ Department of Medical Microbiology and Immunobiology, Faculty of Medicine, University of Szeged, Szeged, Hungary \\ ${ }^{2}$ Department of Pharmacodynamics and Biopharmacy, Faculty of Pharmacy, University of Szeged, Szeged, Hungary \\ *Corresponding author: Márió Gajdács \\ Email:mariopharma92@gmail.com
}

Received: 28 October 2019 / Accepted: 18 December 2019

\begin{abstract}
Introduction: The emergence of multidrug-resistant bacterial strains is a severe global health issue, which is worsened by the inability of new antibiotics. Virulence inhibition is one of the novel strategies that have been proposed to combat bacterial pathogens more effectively, without the risk of exerting selection pressure on these microorganisms. Inhibition of bacterial cell-cell communication (quorum sensing; QS) is a promising approach however, rapid and cost-effective screening for compounds with QS-inhibitory activity is not yet well-established. Aims: The aim of the present study is to determine the ideal experimental conditions for the disk-diffusion based QSinhibitory assay with the most frequently used QS-signal molecule-producing and reporter strains.

Methods: In our study, the effects of growth characteristics, incubation time, temperature and the used culture media were studied on the used bacterial strains and results of the disk-diffusion based QS-inhibitory assay.

Results: Based on our results, the ideal experimental setting includes a modified Luria-Bertani medium (LB*; complemented with nutrients and microelements), incubation at room temperature $\left(25^{\circ} \mathrm{C}\right)$ for 48 hours before the reading of results, where the density of the starting inocula has less influence of the results of the assay.

Conclusion: Establishing standard operating procedures (SOPS) is a way to help carry out various operations, aiming to increase precision and efficiency. Adherence to the experimental settings defined based on our results may aid in improving the reproducibility, comparability and reliability of results obtained by this method.
\end{abstract}

Keywords: standard operating procedures, quorum sensing, QS, disk diffusion, Chromobacterium, violacein, Serratia, prodigiosin, Agrobacterium, pigment

\section{Introduction}

Bacterial infections are still major factors of morbidity and mortality in both developing and developed countries worldwide therefore, antibiotics should be considered medicines of special importance [1]. In addition to being the causal therapy of often life-threatening infections (e.g., sepsis), antibiotics have paved the way for the development of many medical specialities (e.g., complex surgical procedures, organ transplantation, cancer chemotherapy, neonatology) [2, 3]. The continuous emergence of resistance bacterial strains (especially multidrug-resistant [MDR] pathogens) is becoming a severe global health issue $[4,5]$. One of the best ways to combat antimicrobial drug resistance is with the development of novel antibiotic drugs (which was the standard course of conduct during the 1960-1980's), nowadays however, the pharmaceutical companies are struggling to keep up with the continuous and detrimental developments in resistance trends [6,7]. The scarcity of new agents in the 'antibiotic pipeline' could be attributed to economical (antibiotics have high developmental costs and modest returns of investment, development of drugs for chronic illnesses and cancer is much more lucrative), clinical (the difficulties of arranging and tracking clinical trials) and microbiological (the emergence of resistant strains is inevitable) characteristics [8,9]. For this reason, no novel broad-spectrum agent has been developed since the discovery of the fluoroquinolones in the 1980's, while the dynamic increase in the prevalence of resistant isolates has been reported worldwide [10].

Due to the scarcity of available therapeutic options, novel strategies have been proposed to combat bacterial pathogens more effectively $[11,12]$. One of these strategies is combination therapy with the use of existing antibiotics, however, except for some well-defined clinical situations, the clinical utility of antibiotic combinations has been controversial, in addition to their costs for the healthcare infrastructure [13]. Another possible therapeutic alternative is to utilize adjuvant compounds (together with antibiotics) during therapy $[12,14]$. These antimicrobial adjuvants are classified to two distinct categories: Class I adjuvants affect the microorganism, while Class II adjuvants 
affect the cells of the host. Class I adjuvants include examples, such as $\beta$-lactamase inhibitors (which have been successfully used in therapy for many decades against various $\beta$-lactamaseproducing pathogens), bacterial efflux pump inhibitors (e.g., phenylalanine-arginine $\beta$-naphthylamide $(\mathrm{PA} \beta \mathrm{N}$, although these compounds only have relevance in theoretical models and experimental settings for now, because most of them are toxic in the efflux pump inhibitory concentrations)) and modulators of bacterial membrane potential (e.g., loperamide) and compounds inhibiting bacterial toxin synthesis or neutralizing antibodies (e.g., bezlotoxumab against the toxins of Clostridioides difficile) [14,15]. Class I adjuvants may be useful, as they may in theory, make old antibiotics useful again, that have already been eliminated from clinical practice due to their widespread resistance. Class II adjuvants are usually compounds enhancing the immune response of the host organism against the foreign invaders (e.g., streptazolin, as a stimulant of macrophages and natural killer-cells) [14]. Another promising approach to fight bacterial infections is the use of virulence inhibitors: these compounds do not affect the viability of these cells, instead, they inhibit the synthesis or expression of bacterial virulence factors, which are key in their pathogenesis [16]. The potential advantage of these agents is that the selection pressure (and consequently, the chance of resistance development) is expected to be much lower [17].

Quorum sensing (QS; also called autoinduction) is a chemical-sociobiological mechanism of communication, during which bacteria can regulate the expression of specific genes (which are important for benefits in fitness and reproductive success in their niche), in response to the density of cells in the surrounding environment $[18,19]$. This includes the detection of signal molecules produced by surrounding cells and also self-produced signals (leading to positive feed-back; these autoinducers (or bacterial 'pheromones') diffuse into the specific niche, where their concentrations grow proportionally with the number of bacterial cells [20]. If the concentration of these signal molecules reaches a critical concentration (corresponding to a critical population density), these signal molecules initiate the transcription of various target genes [18-20]. Quorum sensing was first described in the marine bacterium Vibrio fischeri, a symbiont in the light organ of some marine animals: if bacteria reach a threshold population density, genes encoding bioluminescence are expressed [21]. QS mediates the expression of various features important in bacterial physiology and virulence, leading to phenotypic changes: expression of toxin genes (e.g., toxic shock syndrome toxin in Staphylococcus aureus, elastase in Pseudomonas aeruginosa, protease in $V$. cholerae), bacterial secretion systems (e.g., Salmonella species), efflux pumps (e.g., P. aeruginosa), biofilmproduction (e.g., P. aeruginosa, Acinetobacter baumannii), induction of bacterial competence (Streptococcus pneumoniae), motility (e.g., P. aeruginosa) and production of pigments (e.g., Chromobacterium violaceum, Serratia marcescens) [22-27]. Quorum sensing has also been implicated in facilitating the spread of antibiotic-resistance genes [18,28-30].

QS signal molecules include a wide range of compounds with distinct structural characteristics [18-20]. In Gram-negative bacteria, derivatives of L-homoserine lactone (acyl-HSLs or AHLs) are the most prevalent, while in Gram-positive bacteria, peptide-based signal molecules (autoinducing peptides, AIPs, which are post-transcriptionally

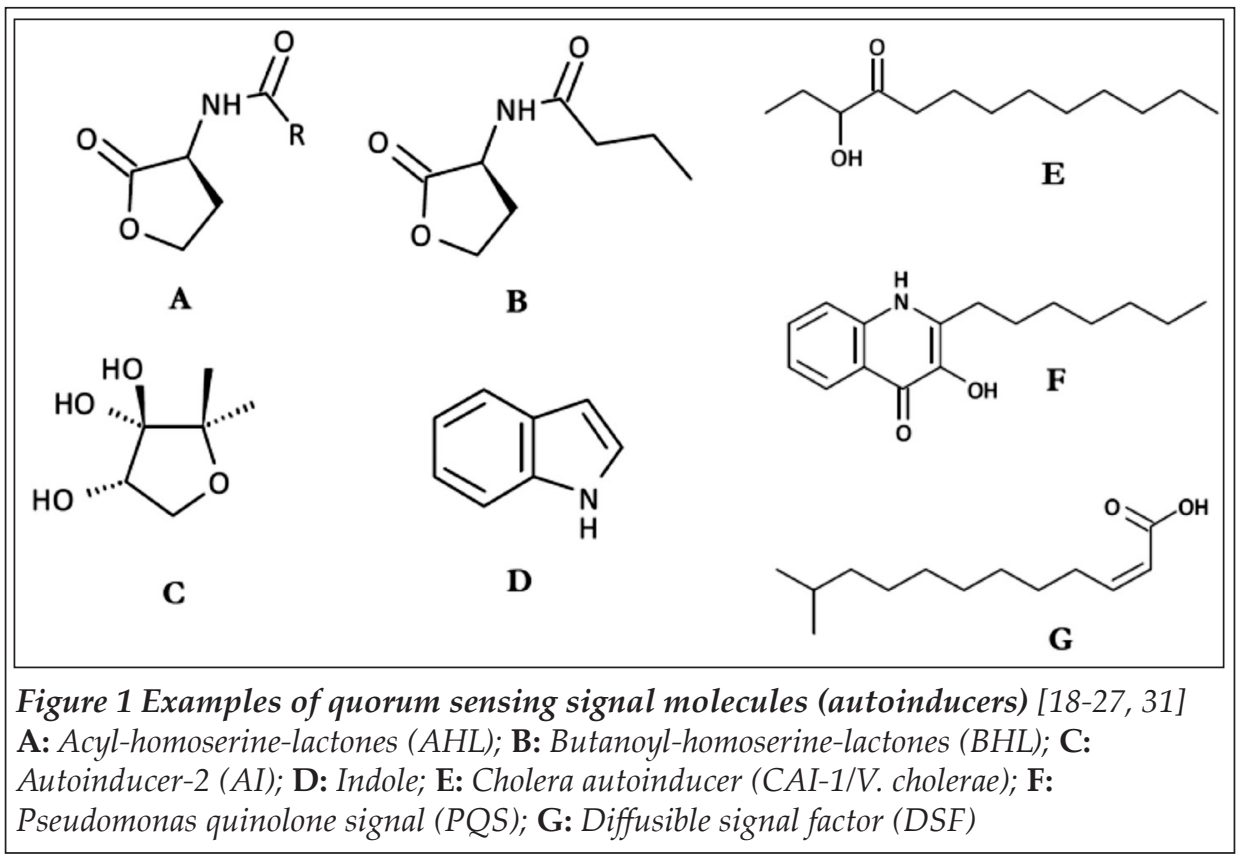


modified small peptides) are most frequently detected. Some signaling molecules are detected by both groups (e.g., AI-2, a derivative of dihydroxy-2,3-pentanedione) (for examples, see Figure 1) [18-23]. Although the signal molecules may differ, the consequent mechanism of activation caused by these molecules is very similar in all bacteria [1823]. In Gram-negative bacteria AHLs may be characterized by the nature and length of the substitution at the 3-carbon position, and the presence of unsaturated chains within the acyl chain $[18,19,31]$.

The elimination or inhibition of QS-signal transmission is termed quorum quenching (QQ) [32]. This may be a consequence of inhibition of autoinducer-synthesis, degradation of signal molecule or through the use of signal-antagonists, inhibiting the sensing of these signal molecules by the relevant bacteria $[19,31,32]$. It is no surprise that many organisms possess enzymes with activity against such signal molecules (e.g., the human paraoxonase (PON, a lactonase) can also degrade AHLs). Synthetic compounds (inhibition-based $Q Q$ ) or enzymes (degradation-based QQ) do not kill pathogenic bacteria, instead they inhibit the signal transduction mechanisms important in the expression of their virulence determinants (thus, disarming them) $[14,16,19,31,32]$. QQ-compounds may be considered as potential therapeutic alternatives in the treatment of bacterial infections, as they are capable of eliminating the disease-causing capacity of bacteria, without the risk of rapid resistance development [18-20, 31-33]. Several in vitro and in vivo model systems have been developed for the qualitative and quantitative evaluation of a compounds QS-inhibitory activity: these methods may include the use of Petri-dish or microplate-based colorimetric methods, molecular biological techniques (e.g., polymerase chain reaction), animal models and transgenic constructs [34-36]. Disk diffusion is a simple method for screening the susceptibility of various microorganisms against drugs/candidate molecules: it is user-friendly, and there is a lot of experience accumulated due to its use in routine clinical microbiology. Disk-diffusion based QS-inhibitory (DDBQSI) assay utilizing QS-signal molecule producing strains and signal molecule-reporter strains (e.g., Agrobacterium, Chromobacterium, Pseudomonas, Serratia and Vibrio species) is the most frequently used method [36-40]. The advantage of this method is its simple execution, the highthroughput nature and its usability in resourcescarce settings [41]. Nevertheless, there are many different and conflicting experimental protocols described for DDBQSI-assays in the literature, which makes it difficult to evaluate and compare published results. Additionally, the reproducibility of positive results still represents an important challenge for laboratories, because growth characteristics and pigment production by these bacteria is also subject to some additional factors [37]. The aim of the present study is to determine the ideal experimental conditions (i.e., incubation time, temperature, culture media) for disk-diffusion based QS-inhibitory (DDBQSI) assays with the most frequently used QS-signal molecule producing and reporter strains, and to establish standard operating procedures (SOPs) to optimize reproducibility of these assays.

\section{Materials and methods}

\subsection{Culture media}

- Mueller-Hinton broth (MH-B) and Mueller-Hinton agar (MH-A) (Bio-Rad Hungary Ltd., Budapest, Hungary)

- Nutrient broth (NB) and Nutrient agar (NA) (Bio-Rad Hungary Ltd., Budapest, Hungary)

- Luria-Bertani broth (LB-B) and Luria-Bertani agar (LB-A) Bio-Rad Hungary Ltd., Budapest, Hungary)

- Modified Luria-Bertani broth (LB*-B) and agar (LB*-A) (which were prepared in-house, containing $8.0 \mathrm{~g}$ tryptone, $5.0 \mathrm{~g}$ yeast extract, $5.0 \mathrm{~g}$ $\mathrm{NaCl}, 2.0$ g glucose, $1.0 \mathrm{~g} \mathrm{~K}_{2} \mathrm{HPO}_{4^{\prime}} 0.2 \mathrm{~g} \mathrm{MgSO}_{4} \mathrm{x}$

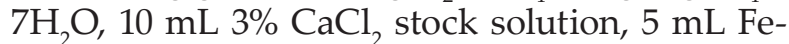
EDTA stock solution, $1 \mathrm{~mL}$ microelement stock solution and $12.0 \mathrm{~g}$ of bacteriological agar in case of the solid medium, per $1 \mathrm{~L}$ of media; $\mathrm{pH}$ was adjusted to 7.0-7.2)

\subsection{Bacterial strains}

The following bacterial strains were used during our experiments:

- Chromobacterium violaceum wt85 [36]

Taxomony: Gram-negative, facultative anaerobic rod, member of the Neisseriales order

Function: wild-type strain (control strain), characterized by the AHL signal molecule-mediated production of the purple violacein pigment, capable of endogenous QS-signal molecule-production (N-hexanoyl-L-HSL)

- C. violaceum CV026 [36] axomony: Gram-negative, facultative anaerobic rod, member of the Neisseriales order 
Function: Tn5 transposase-mutant, AHL-signal molecule indicator strain (produces purple violacein pigment in the presence of AHLs), which is incapable of endogenous QS-signal moleculeproduction, but useful in the detection of external stimuli

- Enterobacter cloacae (clinical isolate no. 31298, isolated from a wound sample) [37]

Taxomony: Gram-negative, facultative anaerobic rod, member of the Enterobacterales order

Function: AHL-producing-strain (used with $C$. violaceum CV026)

- Sphingomonas paucimobilis Ezf 10-17 (isolated from a tumor of the "Ezertüfü" variety of the common grape vine [Vitis vinifera]) [36]

Taxomony: Gram-negative, strict aerobic rod, member of the Sphingomonadales order

Function: AHL-producing-strain (used with C. violaceum CV026)

- Novosphingobium spp. Rr 2-17 (isolated from a tumor of the "Rajnai rizling" variety of the common grape vine [Vitis vinifera]) [36]

Taxonomy: Gram-negative, facultative anaerobic rod, member of the member of the Sphingomonadales order

Function: AHL-producing-strain (used with $C$. violaceum CV026)

- Serratia marcescens AS-1 (Szeged Microbiological Culture Collection) [39]

Taxonomy: Gram-negative, facultative anaerobic rod, member of the Enterobacterales order

Function: characterized by the production AHL signal molecule-mediated production of the orange-red pigment prodigiosin (2-methyl-3-pentyl-6-methoxyprodigiosin), capable of endogenous QS-signal molecule-production (N-hexanoyl-L-HSL)

- A. tumefaciens NTL4(pCF218)(pCF372) (isolated from a tumor of a wild cherry tree [Prunus avium]) $[36,38]$

Taxonomy: Gram-negative, facultative anaerobic rod, member of the Rhizobiales order

Function: characterized by the expression of $\beta$-galactosidase in the presence of a wide range of AHL signals, which may be detected in the presence of X-gal (5-bromo-4-chloro-3-indolyl$\beta$-D-galactopyranoside) in the medium, resulting in a color change

- A. tumefaciens C58 [36,38]

Taxonomy: Gram-negative, facultative anaerobic rod, member of the Rhizobiales order

Function: AHL-producing-strain (used with Agrobacterium tumefaciens NTL4(pCF218)(pCF372))
The bacterial strains for our experiments were kindly provided by Dr. Ernő Szegedi (Institute of Viticulture and Enology, National Agricultural Research Center). The bacterial strains were maintained on Luria-Bertani (LB) agar for shorter time periods ( $<1$ month), while for longer periods, the strains were kept in a $-80^{\circ} \mathrm{C}$ freezer, in a $1: 4$ mixture of $85 \%$ glycerol and liquid Luria-Bertani media. For the maintenance purposes of $C$. violaceum CV026 and A. tumefaciens NTL4(pCF218)(pCF372), media were also supplemented with kanamycin and carbenicillin, respectively $[36,38]$.

\subsection{Chemicals}

Bacteriological agar (Bio-Rad Hungary Ltd.; Budapest, Hungary), tryptone (Thermo Fischer Scientific; Waltham, US), yeast extract (Thermo Fischer Scientific; Waltham, US), D-glucose (Sigma-Aldich; Budapest, Hungary), kanamycin (Sigma-Aldich; Budapest, Hungary), carbenicillin (Sigma-Aldich; Budapest, Hungary), $\mathrm{NaCl}$ (Sigma-Aldich; Budapest, Hungary), $\mathrm{K}_{2} \mathrm{HPO}_{4}$ (Sigma-Aldich; Budapest, Hungary), $\mathrm{KH}_{2} \mathrm{PO}_{4}$ (Sigma-Aldich; Budapest, Hungary), $\mathrm{MgSO}_{4} \times 7 \mathrm{H}_{2} 0$ (Sigma-Aldich; $\mathrm{Bu}$ dapest, Hungary), $\mathrm{CaCl}_{2} \times 2 \mathrm{H}_{2} \mathrm{O}$ (Sigma-Aldich; $\mathrm{Bu}-$ dapest, Hungary), $\mathrm{FeSO}_{4} \times 7 \mathrm{H}_{2} 0$ (Sigma-Aldich; Budapest, Hungary), $\mathrm{Na}_{2}$ EDTA (Sigma-Aldich; Budapest, Hungary), $\mathrm{MnSO}_{4} \times 7 \mathrm{H}_{2} \mathrm{O}$ (Sigma-Aldich; Budapest, Hungary), $\mathrm{ZnSO}_{4} \times 7 \mathrm{H}_{2} \mathrm{O}$ (Sigma-Aldich; Budapest, Hungary), $\mathrm{Na}_{2} \mathrm{MoO}_{4} \times 2 \mathrm{H}_{2} \mathrm{O}$ (Sigma-Aldich; Budapest, Hungary), $\mathrm{CoCl}_{2} \times 6 \mathrm{H}_{2} \mathrm{O}$ (Sigma-Aldich; Budapest, Hungary), dimethyl-sulfoxide (DMSO; Sigma-Aldich; Budapest, Hungary), acridine orange (Sigma-Aldich; Budapest, Hungary) and phosphate buffered saline (PBS; Sigma-Aldich; Budapest, Hungary). During the preparation of the modified Luria-Bertani broth (LB*-B) and agar (LB*-A), the following stock solutions were used: $5 \%$ Fe-EDTA stock solution, $3 \% \mathrm{CaCl}_{2}$ stock solution and a microelement stock solution (containing $1.0 \mathrm{~g} \mathrm{MnSO}_{4} \times 7 \mathrm{H}_{2} \mathrm{O}, 0.5 \mathrm{~g} \mathrm{ZnSO}_{4} \times 7 \mathrm{H}_{2} \mathrm{O}, 25$ $\mathrm{mg} \mathrm{Na} 2 \mathrm{MoO}_{4} \times 2 \mathrm{H}_{2} \mathrm{O}$ and $2.5 \mathrm{mg} \mathrm{CoCl} \mathrm{C}_{2} \times \mathrm{H}_{2} \mathrm{O}$ per $100 \mathrm{~mL}$ ). The stock solutions were aliquoted in 50 $\mathrm{mL}$ centrifuge tubes and kept at $-20^{\circ} \mathrm{C}$.

\subsection{Evaluation of growth characteristics and pigment production of relevant bacterial strains}

To identify the ideal experimental conditions, growth characteristics of the bacterial strains used were determined in Nutrient broth (NB), MuellerHinton (MH-B) and Luria-Bertani (LB-B) broths, 
in addition to Nutrient agar (NA), Mueller-Hinton (MH-A) agar and Luria-Bertani agar (LB-A). In the assays, liquid and solid media were inoculated with the same primary culture for each bacterial strain using a calibrated loop $(10 \mu \mathrm{l})$. The optical density of the liquid media $\left(\mathrm{OD}_{580^{\prime}}\right.$ using a photometer) and the number of colonies as well as the degree of pigment production were observed. Growth properties were

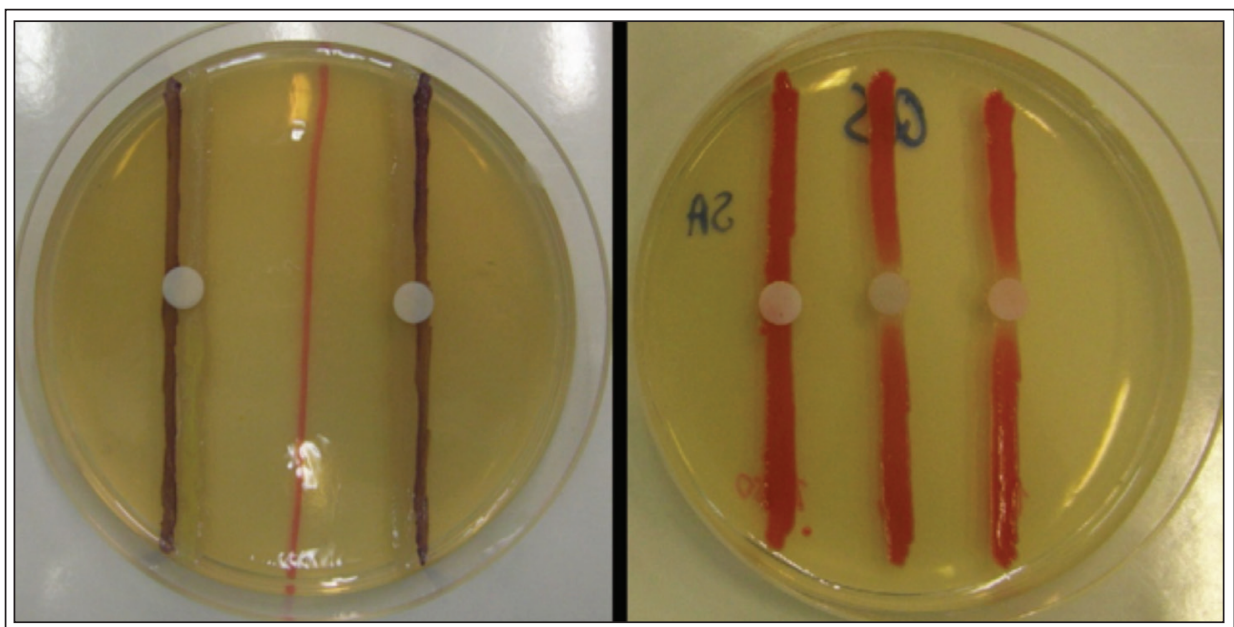

Figure 2 Disk diffusion quorum-sensing inhibitory assay using C. violaceum CV026 and E. cloacae 31298 (left) and S. marcescens AS-1 (right)

studied at four different temperatures of incubation: $0^{\circ} \mathrm{C}$ (refrigerator), $10^{\circ} \mathrm{C}$ (cooled room with controlled temperature), $25^{\circ} \mathrm{C}$ (room temperature) and $37^{\circ} \mathrm{C}$ (incubator). The cultures were measured/read after 12, 24, 48 and 72 hours of incubation. The results of the experiments were from at least three independent experiments. Based on literature data, our study was later complemented with a modified Luria-Bertani (LB*) medium, which was compared to the classical LB medium [42] (see 2.1. Culture media).

\subsection{Disk diffusion quorum-sensing inhibitory assay}

Quorum sensing inhibitory activity was monitored by the disk diffusion method. During the assay, cultures of $\mathrm{OD}_{580} \sim 0.5$ overnight bacteria grown in $\mathrm{LB}^{*}$-B broth were inoculated directly onto $\mathrm{LB}^{*}$-A agar surface. Filter paper disks $(7.0 \mathrm{~mm}$ in diameter, Whatmann $3 \mathrm{MM}$ ), were impregnated with $10 \mu \mathrm{L}$ of acridine orange (AO; used as a positive control; 25.0 $\mathrm{mg} / \mathrm{mL}$ in phosphate buffered saline) or DMSO (used as a negative control, $2 \mathrm{~V} / \mathrm{V} \%$ ) [37]. The disks were placed on the surface of $\mathrm{LB}^{*}$-A agar surface between the parallel inoculations of sensor (C. violaceum CV026) and AHL-producer (S. paucimobilis Ezf 10-17, Novosphingobium spp. Rr 2-17 and E. cloacae 31298) strains; the exception was S. marcescens AS-1 (capable of producing prodigiosin from endogenous AHL-signals), where disks were placed on the center of the inoculated line (Figure 2) [3639]. To quantify the QS inhibitory effect, the diameter of the QS-inhibition zones (i.e., the culture of discolored but intact bacteria) around the disks was measured using a ruler, after 12, 24, 48 and 72 hours of incubation [36-39]. The results of the studies are derived from the average of at least three independent experiments. The $A$. tumefaciens NTL4(pCF218)(pCF372) and A. tumefaciens C58 indicator-AHL-producer pair was not included in this experiment, as the presence of X-gal is required in the media for the colour change to occur.

\section{Results and discussion}

\subsection{Growth characteristics of bacterial strains}

There were no relevant differences detected in the growth rate of bacterial strains between the different liquid broths (NB, MH, LB). The growth of bacterial strains was inhibited at low temperatures $\left(0\right.$ and $\left.10^{\circ} \mathrm{C}\right)$ resulting in $\mathrm{OD}_{580}$ values of $0-0.05,0.05-0.1$ and $0.1-0.2$ for $12,24,48$ and 72 hours of incubation, respectively, which was inadequate to perform further experiments. There was no difference in bacterial growth between $25^{\circ} \mathrm{C}$ and $37^{\circ} \mathrm{C}$ incubations (resulting in $\mathrm{OD}_{580}$ values of 0.4-0.5 after 12 hours (i.e. overnight), 0.8-1 after 24 hours, and $>1$ after 48 hours), except in the case of C. violaceum wt85 and C. violaceum CV026, where higher reads were observed at $37^{\circ} \mathrm{C}$, but in both cases, the OD of the bacterial cultures was appropriate for performing further experiments. The use of 48 hour- and 72 hour-cultures is not recommended, due to the accumulation of dead bacterial cells and autolysis, a consequence of the depletion of nutrients in the culture media (in fact, the $\mathrm{OD}_{580}$ values after 72 hours showed decreasing tendencies), which may lead to distorted results in the experiments later on. Similarly, there were no relevant differences detected in the growth rate of 
bacterial strains between the solid agar media (NB, MH-B and LB-B). It should be highlighted, that in case of $S$. marcescens, the temperature had a pronounced effect on pigment production in both liquid and solid media (pigment production ceased at $37^{\circ} \mathrm{C}$, this effect was not observed for $C$. violaceum wt85). For this reason, $25^{\circ} \mathrm{C}$ was set as the reference temperature for the additional experiments.

Based on previous reports, it was found that the concentration of several metal ions in the environment has a pronounced effect of quorum sensing in bacteria [37]. After a thorough literature survey, an additional medium was included in our optimization studies, namely the modified LB (or LB*) broth and solid media, which is supplemented by additional nutrients and a microelement solution (containing various metal ions) [42]. The tested strains showed no relevant differences in the growth characteristics in LB-B and LB*-B broths in the same experimental setup previously described. However, during the comparison of LB-A and $\mathrm{LB}^{*}$-A solid media, it was evident that colony formation (number and size of bacterial colonies) and pigmentation of the colonies occurred more rapidly, therefore, the growth properties of the relevant strains were further characterized on this media (Table I). During the bacterial growth experiments on the LB*-A solid media, it was observed that bacterial colonies' growth and pigment production on LB ${ }^{*}$ agar were stable after 48 hours when incubated at $25^{\circ} \mathrm{C}$. In addition, if the read-

Table I Growth characteristics of tested QS-strains on $L B^{*}$-A media at room temperature $\left(25^{\circ} \mathrm{C}\right)$

\begin{tabular}{|c|c|c|c|c|c|}
\hline \multirow[b]{2}{*}{ After 24 hours } & \multicolumn{5}{|c|}{ Optical density $\left(\mathrm{OD}_{580}\right)$ of bacterial inoculum used } \\
\hline & 0.1 & 0.3 & 0.5 & 0.7 & 1.0 \\
\hline Chromobacterium violaceum CV026 & $\varnothing$ & $\varnothing /+$ & + & + & ++ \\
\hline Chromobacterium violaceum wt85 & $\varnothing$ & $\varnothing /+$ & + & + & $++(!)$ \\
\hline Sphingomonas paucimobilis Ezf 10-17 & $\varnothing /+$ & $\varnothing /+$ & + & ++ & ++ \\
\hline Novosphingobium spp. Rr 2-17 & $\varnothing$ & $\varnothing$ & $\varnothing$ & + & + \\
\hline Serratia marcescens AS-1 & ++ & ++ & +++ & +++ & +++ \\
\hline Enterobacter cloacae 31298 & ++ & ++ & ++ & +++ & +++ \\
\hline Agrobacterium tumefaciens NTL4 & $-/+$ & $-/+$ & + & ++ & ++ \\
\hline Agrobacterium tumefaciens C58 & $-1+$ & $-/+$ & + & ++ & ++ \\
\hline After 48 hours & 0.1 & 0.3 & 0.5 & 0.7 & 1 \\
\hline Chromobacterium violaceum CV026 & ++ & +++ & +++ & +++ & +++ \\
\hline Chromobacterium violaceum wt85 & $+++(!)$ & $+++(!)$ & $+++(!)$ & $+++(!)$ & $+++(!)$ \\
\hline Sphingomonas paucimobilis Ezf 10-17 & ++ & ++ & +++ & +++ & +++ \\
\hline Novosphingobium spp. Rr 2-17 & ++ & ++ & ++ & ++ & +++ \\
\hline Serratia marcescens AS-1 & $+++(!)$ & $+++(!)$ & $++++(!)$ & $++++(!)$ & $++++(!)$ \\
\hline Enterobacter cloacae 31298 & +++ & +++ & +++ & +++ & +++ \\
\hline Agrobacterium tumefaciens NTL4 & +++ & +++ & +++ & +++ & +++ \\
\hline Agrobacterium tumefaciens C58 & +++ & +++ & +++ & +++ & +++ \\
\hline After 72 hours & 0.1 & 0.3 & 0.5 & 0.7 & 1 \\
\hline Chromobacterium violaceum CV026 & +++ & +++ & +++ & +++ & +++ \\
\hline Chromobacterium violaceum wt85 & $+++(!)$ & $+++(!)$ & $+++(!)$ & $+++(!)$ & $+++(!)$ \\
\hline Sphingomonas paucimobilis Ezf 10-17 & +++ & +++ & +++ & +++ & +++ \\
\hline Novosphingobium spp. Rr 2-17 & ++ & +++ & +++ & ++++ & ++++ \\
\hline Serratia marcescens AS-1 & $+++(!)$ & $+++(!)$ & $++++(!)$ & $++++(!)$ & $++++(!)$ \\
\hline Enterobacter cloacae 31298 & +++ & +++ & ++++ & ++++ & ++++ \\
\hline Agrobacterium tumefaciens NTL4 & +++ & +++ & ++++ & ++++ & ++++ \\
\hline Agrobacterium tumefaciens C58 & +++ & +++ & ++++ & ++++ & ++++ \\
\hline
\end{tabular}

Legend: ø: no growth, +: weak bacterial growth, ++: moderate bacterial growth, +++: adequate bacterial growth, ++++: strong bacterial growth (!): pigment production 
ing of the plates occurred after 48 hours, the colony growth and pigment production has shown to be independent from the optical density of the initial inoculum in the range $\mathrm{OD}_{580} \geq 0.5$, while this number was $\mathrm{OD}_{580} \geq 0.1$ if the reading occurred after 72 hours (Table I).

\subsection{Disk-diffusion quorum-sensing inhibitory assay}

The results of the optimization experiments with the positive control acridine orange $(\mathrm{AO})$ are presented in Table II, where the quorum-sensing inhibition zones are shown for the parallel inoculations between QS-sensor strain C. violaceum and the AHL-producer strains, and for $S$. marcescens AS-1, respectively (Figure 3). No quantifiable QSinhibition zone (i.e. loss of purple violacein pigmentation) was detected in case of the CV026AHL-producers after 12 hours, at least 24 hours were needed for the discoloration to develop, except for the S. marcescens AS-1, where minor inhibition was present. Based on our results, the inhibition zone was still subject to change at the 24 hour-reading of plates, however, the results after 48 hours may be considered to be final, additional incubation and observation did not change the results. According to the data presented, the Serratia model system was the most sensitive for the QSinhibitory activity of AO. DMSO was used as a negative control, no measureable QS-inhibition zone was detected.

\section{Conclusions}

The emergence of multidrug resistance in bacterial infections significantly hinders the appropriate therapy of patients, and with the current disinterest of pharmaceutical companies to develop new antibiotics, alternative approaches should be considered for the therapy of these infections. Quorum sensing is a form of bacterial cell-cell communication, whereby these microorganisms use diffusible signal molecules as proxy to detect the

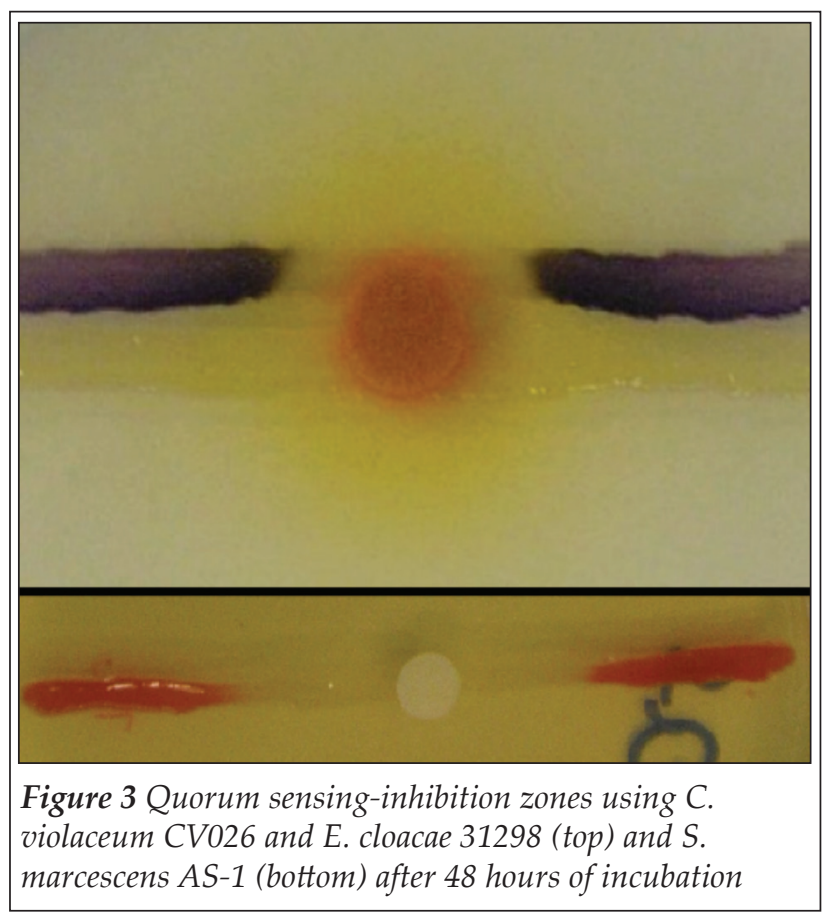

surrounding cell density and produce metabolically costly products when the sufficient biomass has been reached. Inhibitors of quorum sensing may be potent modulators of bacterial virulence, eliminating their pathogenic potential, without killing them (therefore the selection pressure would be lower), however, the development and screening for the QS-activity of these compounds is not well-established. A standard operating procedure (SOP) is a designated set of step-by-step instructions compiled by relevant (qualified) individuals or an organization to help carry out various operations, aiming to increase precision and efficiency. The aim of our study was to characterize the appropriate conditions for the disk diffusion-based QS-inhibition assay, consisting of QSsignal sensor and AHL-producer strains. Based on our results, the ideal experimental setting includes a modified Luria-Bertani medium (complemented with nutrients and microelements), incubation at room temperature $\left(25^{\circ} \mathrm{C}\right)$ for 48 hours before reading of the results, where the density of the starting

Table II Quorum-sensing inhibitory activity of acridine orange (OA) in various model systems, corresponding to different plate-reading times

Quorum-sensing inhibition zone diameter ( $\mathrm{mm} \pm \mathrm{SD})$

\begin{tabular}{|c|c|c|c|c|}
\hline Bacterial model system & 12 hours & 24 hours & 48 hours & 72 hours \\
\hline C. violaceum CV026 + E. cloacae 31298 & $\varnothing$ & $13 \pm 2.2$ & $14 \pm 1.2$ & $14 \pm 1.2$ \\
\hline C. violaceum CV026 + S. paucimobilis Ezf 10-17 & $\varnothing$ & $14 \pm 1.6$ & $16 \pm 0.9$ & $16 \pm 0.9$ \\
\hline Novosphingobium spp. Rr 2-17 & $\varnothing$ & $11 \pm 2.0$ & $13 \pm 1.0$ & $13 \pm 1.0$ \\
\hline Serratia marcescens AS-1 & $6 \pm 2.3$ & $17 \pm 1.5$ & $19 \pm 0.8$ & $19 \pm 0.8$ \\
\hline
\end{tabular}


inocula has less influence of the results of the assay. Adherence to the abovementioned criteria may aid in improving the reproducibility, comparability and reliability of results obtained by this method.

\section{Acknowledgements}

The authors would like to thank Dr. Ernő Szegedi (Institute of Viticulture and Enology, National Agricultural Research Center) for providing the bacterial strains used in our experiments. Part of this study was presented at the $18^{\text {th }}$ International Congress of the Hungarian Society for Microbiology (MMT; Budapest, Hungary).

\section{Competing interests}

The authors declare no conflict of interest, monetary or otherwise.

\section{References}

1. Gaynes, R. The Discovery of Penicillin-New Insights after More Than 75 Years of Clinical Use. Emerg. Infect. Dis. 2017; 23: 849-853. https://doi. org/10.3201/eid2305.161556

2. Laxminarayan, R., Duse, A., Wattal, C., Zaidi, A.K.M., Wertheim, H.F.L., Sumpradit, N., Vlieghe, E., Hara, G.L., Gould, I.M., Goossens, H., et al. Antibiotic resistance-the need for global solutions. Lancet Infect. Dis. 2013; 13: 1057-1098. https://doi. org/10.1016/S1473-3099(13)70318-9

3. Gajdács, M., Paulik, E., Szabó, A. [The opinions of community pharmacists related to antibiotic use and resistance]. Acta Pharm. Hung. 2018; 88: 249252.

4. O'Neill, J. Antimicrobial Resistance: Tackling a Crisis for the Health and Wealth of Nations. Available online: https://amr-review.org/sites/default/files/ AMRReviewPaper-Tacklingacrisisforthehealthandwealthofnations_1.pdf (accessed on 10 October 2019)

5. Boucher, H.W., Talbot, G.H., Bradley, J.S., Edwards, J.E., Gilbert, D., Rice, L.B., Scheld, M., Spellberg, B., Bartlett, J. Bad Bugs, No Drugs: No ESKAPE! An Update from the Infectious Diseases Society of America. Clin. Infect. Dis. 2009; 48: 1-12. https://doi. org/10.1086/595011

6. Lyddiard, D.; Jones, G.L.; Greatrex, B.W. Keeping it simple: Lessons from the golden era of antibiotic discovery. FEMS Microbiol. Lett. 2016; 363, fnw084. https://doi.org/10.1093/femsle/fnw084

7. Gajdács, M., Albericio, F. Antibiotic Resistance: From the Bench to Patients. Antibiotics 2019; 8: 129. https:// doi.org/10.3390/antibiotics8030129

8. Lewis, K. Platforms for antibiotic discovery. Nat. Rev. Drug Discov. 2013; 12: 371-387. https://doi. org/10.1038/nrd3975

9. Projan, S.J. Why is big Pharma getting out of antibac- terial drug discovery? Curr. Opin. Microbiol. 2003; 6: 427-430. https://doi.org/10.1016/j.mib.2003.08.003

10. Gajdács, M. The Concept of an Ideal Antibiotic: Implications for Drug Design. Molecules 2019, 24: 892. https://doi.org/10.3390/molecules24050892

11. Liu, Y., Li, R., Xiao, X., Wang, Z. Antibiotic adjuvants: an alternative approach to overcome multidrug resistant Gram-negative bacteria. Crit. Rev. Microbiol. 2019; 45: 301-314. https://doi.org/10.1080/ 1040841X.2019.1599813

12. Douafer, H., Andrieu, V., Phanstiel, O., Brunel J.M. Antibiotic Adjuvants: Make Antibiotics Great Again! J. Med. Chem. 2019; 62: 8665-8681. https:// doi.org/10.1021/acs.jmedchem.8b01781

13. Ahmed, A., Azim, A., Gurjar, M., Baronia, A.K. Current concepts in combination antibiotic therapy for critically ill patients. Indian J. Crit. Care Med. 2014; 18: 310-314. https://doi.org/10.4103/09725229.132495

14. Wright, G.D. Antibiotic Adjuvants: Rescuing Antibiotics from Resistance. Trends Microbiol. 2016; 24: 862-871. https://doi.org/10.1016/j.tim.2016.06.009

15. Spengler, G., Kincses, A., Gajdács, M., Amaral, L. New Roads Leading to Old Destinations: Efflux Pumps as Targets to Reverse Multidrug Resistance in Bacteria. Molecules 2017; 22: 498. https://doi. org/10.3390/molecules22030468

16. Martínez, O.F., Cardoso, M.A., Ribeiro, S.M., Franco, O.L. Recent Advances in Anti-virulence Therapeutic Strategies With a Focus on Dismantling Bacterial Membrane Microdomains, Toxin Neutralization, Quorum-Sensing Interference and Biofilm Inhibition. Cell. Infect. Microbiol. 2019; 9: 74. https:// doi.org/10.3389/fcimb.2019.00074

17. Totsika, M. Disarming pathogens: benefits and challenges of antimicrobials that target bacterial virulence instead of growth and viability. Future Med. Chem. 9: 267-269. https://doi.org/10.4155/fmc-2016-0227

18. Miller, M.B., Bassler, B.L. Quorum Sensing in Bacteria. Ann. Rev. Microbiol. 2001; 55: 165-199. https:// doi.org/10.1146/annurev.micro.55.1.165

19. Rampioni, G., Leoni, L., Williams, P. The art of antibacterial warfare: Deception through interference with quorum sensing-mediated communication. Bioorg. Chem. 2014; 55: 60-68. https://doi. org/10.1016/j.bioorg.2014.04.005

20. Cegelski, L., Marshall, G.R., Eldridge, G.R., Hultgren, S.J. The biology and future prospects of antivirulence therapies. Nat. Rev. Microbiol. 6: 17-27. https://doi.org/10.1038/nrmicro1818

21. Eberhard, A., Widrig, C.A., McBath, P., Schineller, J.B. Analogs of the autoinducer of bioluminescence in Vibrio fischeri. Arch. Microbiol. 1986; 146: 35-40. https://doi.org/10.1007/BF00690155

22. Gajdács, M. The Continuing Threat of MethicillinResistant Staphylococcus aureus. Antibiotics 2019; 8: 52. https://doi.org/10.3390/antibiotics8020052

23. McCartell, L.L. Dual flagellar systems enable motility under different circumstances. J. Mol. Microbiol. Biotechnol. 2004; 7: 18-29. https://doi. org/10.1159/000077866

24. Surette, M.G., Miller, M.B., Bassler, B.L. Quorum sensing in Escherichia coli, Salmonella typhimurium, and Vibrio harveyi: A new family of genes re- 
sponsible for autoinducer production. Proc. Natl. Acad. Sci. USA. 1999; 96: 1639-1644. https://doi. org/10.1073/pnas.96.4.1639

25. Van Hourdt, R., Givskov, M., Michiels, C.W. Quorum sensing in Serratia. FEMS Microbiol. Rev. 2017; 31: 407-424. https://doi.org/10.1111/j.15746976.2007.00071.x

26. Lee, J., Zhang, L. The hierarchy quorum sensing network in Pseudomonas aeruginosa. Protein Cell. 2015; 6: 26-41. https://doi.org/10.1007/s13238-014-0100-x

27. Griffith, F. The Significance of Pneumococcal Types. J. Hyg. (Lond) 1928; 27: 113-159. https://doi. org/10.1017/S0022172400031879

28. Gajdács, M. [The significance of bacterial quorum sensing (QS) inhibition in antivirulence therapy]. Bodó, B., Szoták, S. (Eds.) Diszciplínák találkozásanyelvek és kultúrák érintkezése. Budapest, Hungary Külgazdasági és Külügyminisztérium, 2018; pp. 394-406.

29. Swift, S., Karlyshev, A.V., Fish, L., Durant, E.L., Winson, M.K., Chhabra, S.R., Williams, P., Macintyre, S., Stewart, G.S. Quorum sensing in Aeromonas hydrophila and Aeromonas salmonicida: identification of the LuxRI homologs AhyRI and AsaRI and their cognate N-acylhomoserine lactone signal molecules. J. Bacteriol. 1997; 179: 5271-5281. https://doi. org/10.1128/JB.179.17.5271-5281.1997

30. Gajdács, M. Resistance trends and epidemiology of Aeromonas and Plesiomonas infections (RETEPAPI): a 10-year retrospective survey. Infect. Dis (Lond). 2019; 51: 710-713. https://doi.org/10.1080/23 744235.2019.1640389

31. Jayaraman, A., Wood, T.K. Bacterial quorum sensing: signals, circuits, and implications for biofilms and disease. Annu. Rev. Biomed. Eng. 2008; 10: 145-167. https://doi.org/10.1146/annurev.bioeng.10.061807.160536

32. Grandclément, C., Tannières, M., Moréra, S., Dessaux, Y., Faure, D. Quorum quenching: role in nature and applied developments. FEMS Microbiol. Rev. 2016; 40: 86-116. https://doi.org/10.1093/femsre/fuv038

33. Clatworthy, A.E., Pierson, E., Hung, D.T. Targeting virulence: a new paradigm for antimicrobial therapy. Nat. Chem. Biol. 2007; 3: 541-548. https://doi. org/10.1038/nchembio.2007.24
34. Christensen, L.D., van Gennip, M., Jakobsen, T.H., Givskov, M., Bjarnsholt, T. Imaging N-acyl homoserine lactone quorum sensing in vivo. Methods Mol. Biol. 2011; 692: 147-157. https://doi.org/10.1007/9781-60761-971-0_11

35. Jakobsen, T.H., van Gennip, M., Christensen, L.D., Bjarnsholt, T., Givskov, M. Qualitative and quantitative determination of quorum sensing inhibition in vitro. Methods Mol. Biol. 2011; 692: 253-263. https:// doi.org/10.1007/978-1-60761-971-0_18

36. Cha, C., Gao, P., Chen, C.Y., Shaw, P.D., Farrand, S.K. Production of acyl-homoserine lactone quorumsensing signals by gram-negative plant-associated bacteria. Mol. Plant. Microbe Interact. 1998; 11: 11191129. https://doi.org/10.1094/MPMI.1998.11.11.1119

37. Kincses, A., Varga, B., Csonka, Á, Sancha, S. Mulhovo, S., Maduerira, A.M., Ferreria, M.J.U., Spengler, G. Bioactive compounds from the African medicinal plant Cleistochlamys kirkii as resistance modifiers in bacteria. Phytotherapy Res. 2018; 32: 1039-1045. https://doi.org/10.1002/ptr.6042

38. Sciaky, D., Montoya, A.L., Chilton, M.D. Fingerprints of Agrobacterium Ti plasmids. Plasmid 1978; 1: 238253. https://doi.org/10.1016/0147-619X(78)90042-2

39. Morohoshi, T., Shiono, T., Takidouchi, K., Kato, M., Kato, N., Kato, J., Ikeda, T. Inhibition of quorum sensing in Serratia marcescens AS-1 by synthetic analogs of $\mathrm{N}$-acylhomoserine lactone. Appl. Environ. Microbiol. 2007; 73: 6339-6344. https://doi. org/10.1128/AEM.00593-07

40. Utari, P.D., Setroikromo, R., Melgert, B.N., Quax, W.J. PvdQ Quorum Quenching Acylase Attenuates Pseudomonas aeruginosa Virulence in a Mouse Model of Pulmonary Infection. Front. Cell. Infect. Microbiol. 2018; 8: 119. https://doi.org/10.3389/ fcimb.2018.00119

41. Gajdács, M. Epidemiology and Resistance Levels of Enterobacteriaceae Isolates from Urinary Tract Infections Expressed as Multiple Antibiotic Resistance (MAR) Indices. J. Pharm. Res. Int. 2019; 29: 1-7. https://doi.org/10.9734/jpri/2019/v29i330238

42. Nacsa-Farkas, E., Kerekes, B.E., Hargitai, F., Vágvölgyi, C., Szegedi, E. Culture media supplemented with inorganic salts improve the growth and viability of several bacterial strains. Acta Biol. Szeged. 2016; 60: 151-156. 